\title{
Indacaterol/glycopyrronium versus salmeterol/ fluticasone in Asian patients with COPD at a high risk of exacerbations: results from the FLAME study
}

\section{Jadwiga A Wedzicha' \\ Nanshan Zhong ${ }^{2}$ \\ Masakazu Ichinose ${ }^{3}$ \\ Michael Humphries ${ }^{4}$ \\ Robert Fogel ${ }^{5}$ \\ Chau Thach ${ }^{5}$ \\ Francesco Patalano 6 \\ Donald Banerji ${ }^{5}$}

'National Heart and Lung Institute, Imperial College London, London, UK; ${ }^{2}$ State Key Laboratory of Respiratory Disease, National Clinical Research Center of Respiratory Disease, Guangzhou Institute of Respiratory Disease, The First Affiliated Hospital of Guangzhou Medical University, Guangzhou, Guangdong, People's Republic of China; ${ }^{3}$ Department of Respiratory Medicine, Tohoku University Graduate School of Medicine, Sendai, Japan; ${ }^{4}$ Beijing Novartis Pharma Co. Ltd., Shanghai, People's Republic of China; ${ }^{5}$ Novartis Pharmaceuticals Corporation, East Hanover, NJ, USA; ${ }^{6}$ Novartis Pharma AG, Basel, Switzerland

\author{
This article was published in the following Dove Press journal: \\ International Journal of COPD \\ 19 January 2017 \\ Number of times this article has been viewed
}

Background: The FLAME study demonstrated that indacaterol/glycopyrronium (IND/GLY), the fixed-dose combination of a long-acting $\beta_{2}$-agonist (LABA, IND) and a long-acting muscarinic antagonist (LAMA, GLY), was superior to salmeterol/fluticasone combination (SFC) in preventing exacerbations in COPD patients with a high risk of exacerbations. In this study, we report a prespecified analysis of the efficacy and safety of IND/GLY versus SFC in Asian patients from the FLAME study.

Patients and methods: Patients from Asian centers with moderate-to-very severe COPD and $\geq 1$ exacerbation in the previous year from the 52-week, randomized FLAME study were included. IND/GLY was compared versus SFC for effects on exacerbations, lung function (forced expiratory volume in 1 second $\left[\mathrm{FEV}_{1}\right]$ and forced vital capacity [FVC]), health status (St George's Respiratory Questionnaire [SGRQ]), rescue medication use, and safety.

Results: A total of 510 Asian patients (IND/GLY, $n=250$ or SFC, $n=260$ ) were included. Compared to the overall FLAME population, the Asian cohort had more males, a shorter duration of COPD, fewer patients using inhaled corticosteroid (ICS) at screening, fewer current smokers, and more patients with very severe COPD. IND/GLY significantly reduced the rate of moderate/severe exacerbations (rate ratio: $0.75 ; 95 \%$ confidence interval: $0.58-0.97 ; P=0.027$ ) and prolonged time to first moderate/severe exacerbation versus SFC (hazard ratio: $0.77 ; 95 \%$ confidence interval: $0.59-1.01 ; P=0.055)$. Predose trough $\mathrm{FEV}_{1}$ and $\mathrm{FVC}$ significantly improved in Asian patients $(P<0.001)$. IND/GLY improved SGRQ for COPD (SGRQ-C score; $P=0.006$ ) and reduced rescue medication use $(P=0.058)$ at week 52 . Pneumonia incidence was $3.6 \%$ with IND/GLY and $7.7 \%$ with SFC $(P=0.046)$.

Conclusion: In exacerbating Asian COPD patients, IND/GLY was more effective than SFC. Keywords: Asia, bronchodilator agents, chronic obstructive pulmonary disease, exacerbations, indacaterol/glycopyrronium

\section{Introduction}

COPD is a progressive disease characterized by partially reversible airflow limitation and poses a major health care and socioeconomic burden. ${ }^{1-4}$ Differences in disease prevalence and clinical practice for COPD exist between Asian and other populations, including higher rates of COPD-associated mortality and morbidity due to differences in exposure to tobacco use, environmental pollutants, health care management structure, and cultural differences. ${ }^{5,6}$ Patients with COPD are prone to experiencing exacerbations, which clinically manifest as an acute worsening of symptoms that is
Correspondence: Jadwiga A Wedzich National Heart and Lung Institute, Imperial College London, G05, Emmanuel Kaye Building, Royal Brompton Campus, Ib Manresa Road, London SW3 6LR, UK Tel +44 2075947947

Email j.wedzicha@imperial.ac.uk 
beyond normal day-to-day variations and leads to a change in the treatment regimen. ${ }^{7}$ Exacerbations are a significant cause of morbidity, mortality, and increased health care costs. ${ }^{8}$ Hence, prevention of exacerbations is important in the clinical management of COPD, and treatments that can prevent exacerbations would have beneficial effects on patients' health status and disease outcomes. ${ }^{9}$ Combination of LABA and ICS (LABA/ICS) or LAMA monotherapy has been recommended by most COPD treatment guidelines as the first choice of treatment for COPD patients with a high risk of exacerbation. ${ }^{10,11}$ However, LABA/ICS combination therapy is associated with an increased risk of pneumonia, along with other steroid-related adverse effects. ${ }^{12,13} \mathrm{~A}$ dual bronchodilator regimen of LABA/LAMA is an attractive alternative to the LABA/ICS combination in COPD patients at risk of exacerbations. ${ }^{14}$ Prospective exploratory analyses showed for the first time in the LANTERN study that a fixeddose combination of IND (a LABA) and GLY (a LAMA) was more effective in reducing exacerbations compared with SFC (a LABA/ICS) in patients with moderate-to-severe COPD. ${ }^{15}$ In Asian patients, IND/GLY was shown to be superior over monobronchodilators in improving lung function, symptoms, and health status and reducing exacerbations without any safety concerns. ${ }^{16}$ The recently reported subgroup analysis of the SHINE study demonstrated that IND/GLY showed superior efficacy and comparable safety compared with its monocomponents, open-label tiotropium, and placebo in Japanese patients with moderate-to-severe COPD. ${ }^{17}$

The 52-week FLAME study was the first study to demonstrate that IND/GLY was superior to SFC in reducing the risk of exacerbations in patients with moderate-to-very severe COPD with a high exacerbation risk. ${ }^{18}$ The FLAME study provided an opportunity to assess the efficacy of IND/ GLY in COPD patients from different regions; the study included $\sim 15 \%$ of patients from Asia. As ethnic differences between the Western and Asian population, including those in the pathogenesis of COPD and its natural course, genetic makeup, clinical practice, and pharmacogenomics could influence the relative efficacy and safety of available therapies, it is important to assess the efficacy and safety of new therapies specifically within this population. In this study, we present the results from a comprehensive analysis of the efficacy and safety of IND/GLY in Asian COPD patients from the FLAME study.

\section{Patients and methods}

\section{Study design}

This was a prespecified analysis of Asian patients from the multicenter, randomized, double-blind, double-dummy, parallel-group, noninferiority, active-controlled FLAME study.

\section{Patients}

The FLAME study enrolled male or female patients aged $\geq 40$ years with stable COPD and moderate-to-very severe airflow limitation (GOLD 2011 criteria). Eligible patients had a postbronchodilator $\mathrm{FEV}_{1} \geq 25 \%$ and $<60 \%$ predicted and postbronchodilator $\mathrm{FEV}_{1} / \mathrm{FVC}<0.70$ at the start of the run-in period. Patients were included if they had a documented history of $\geq 1$ COPD exacerbation (that required treatment with systemic corticosteroids and/or antibiotics) in the previous 12 months and a dyspnea mMRC grade $\geq 2$ at the start of the run-in period. Patients were excluded from the study if they had an exacerbation that required treatment with antibiotics and/or systemic corticosteroids and/or hospitalization in the 6 weeks prior to screening and during the run-in period; patients with a blood eosinophil count of $>600 / \mathrm{mm}^{3}$ at the start of run-in were also excluded.

The study protocol and all amendments were reviewed and approved by the IEC or IRB for each center. For a full list of the ethics committees please view them here. This trial is registered at ClinicalTrials.gov (NCT01782326). The study was conducted in accordance with the ethical principles of the Declaration of Helsinki. Written informed consent was obtained from all patients.

\section{Treatments}

Eligible patients were randomized (1:1) to receive either IND/GLY 110/50 $\mu \mathrm{g}$ q.d. or SFC 50/500 $\mu \mathrm{g}$ b.i.d. for 52 weeks, with a 30-day follow-up. At screening, patients were provided with a short-acting $\beta_{2}$-agonist (salbutamol or albuterol) inhaler to use as rescue medication on an "as needed" basis throughout the study.

\section{Study outcomes}

\section{Exacerbation end points}

Efficacy of IND/GLY was compared with SFC, primarily in terms of rate of all (mild, moderate, or severe) COPD exacerbations (primary end point of the overall FLAME study), rate of moderate/severe COPD exacerbations, and time to first moderate/severe COPD exacerbation (secondary end points of the overall FLAME study). Exacerbations were defined as per the standard Anthonisen criteria ${ }^{19,20}$ and were categorized as mild (worsening of symptoms for $>2$ consecutive days, not treated with systemic corticosteroids and/or antibiotics), moderate (requiring treatment with systemic corticosteroids or antibiotics or both), and severe (leading to patient hospitalization [emergency room visit of $>24$ hours considered 
as a hospitalization] in addition to treatment with systemic corticosteroids and/or antibiotics).

\section{Other efficacy end points}

Lung function (predose $\mathrm{FEV}_{1}$ and predose FVC after 4, 12, 26,38 , and 52 weeks of treatment), health status (SGRQ-C total score after 4, 12, 26, 38, and 52 weeks of treatment), and rescue medication use (number of puffs taken in the previous 12 hours recorded in the morning and evening by the patient using eDiary) were also assessed during 52 weeks of treatment.

\section{Safety assessments}

Safety assessments included incidence of treatment-emergent AEs, SAEs, AEs suspected to be related to study drug, deaths, and time to first pneumonia (consolidated term). All cases of pneumonia were confirmed by CXR.

\section{Statistical analysis}

The full analysis set and safety set included all randomized patients who received at least 1 dose of double-blind drug. The number of exacerbations during the 52-week treatment period was analyzed using a negative binomial model including terms for treatment, smoking status at baseline, ICS use at screening, baseline severity of airflow limitation, and region as fixed effects. The model also contained baseline total symptom score and number of exacerbations in the year prior to screening, as covariates. The time-to-event end points were analyzed using a Cox regression model that included the same terms as the negative binomial model. The primary noninferiority analysis was powered based on the overall sample size. This study was not designed to demonstrate noninferiority in any cohort, including the Asian cohort. A chi-square test was performed to assess whether there was a significant difference between IND/GLY and SFC in the pneumonia rate.

\section{Results}

\section{Study population}

A total of 510 (IND/GLY, n=250; SFC, n=260) patients (295 from China, 5 from Hong Kong, 80 from Japan, 35 from The Philippines, 71 from Korea, 16 from Taiwan, and 8 from Thailand) were included in this analysis (Table S1), representing $15.2 \%$ of the overall FLAME study population. The rates of discontinuation from double-blind treatment were $11.2 \%$ versus $12.3 \%$ in the IND/GLY and SFC groups (Figure 1). A total of 505 patients (IND/GLY, $n=247$; SFC, $\mathrm{n}=258$ ) were included in the full analysis set.

Overall, the Asian cohort had a higher proportion of males, with a lower BMI, shorter duration of COPD, fewer patients who used ICS at screening, a lower percentage of current smokers, and a higher proportion of patients with very severe COPD compared with the overall population (Table 1). The majority of patients in the Asian cohort were

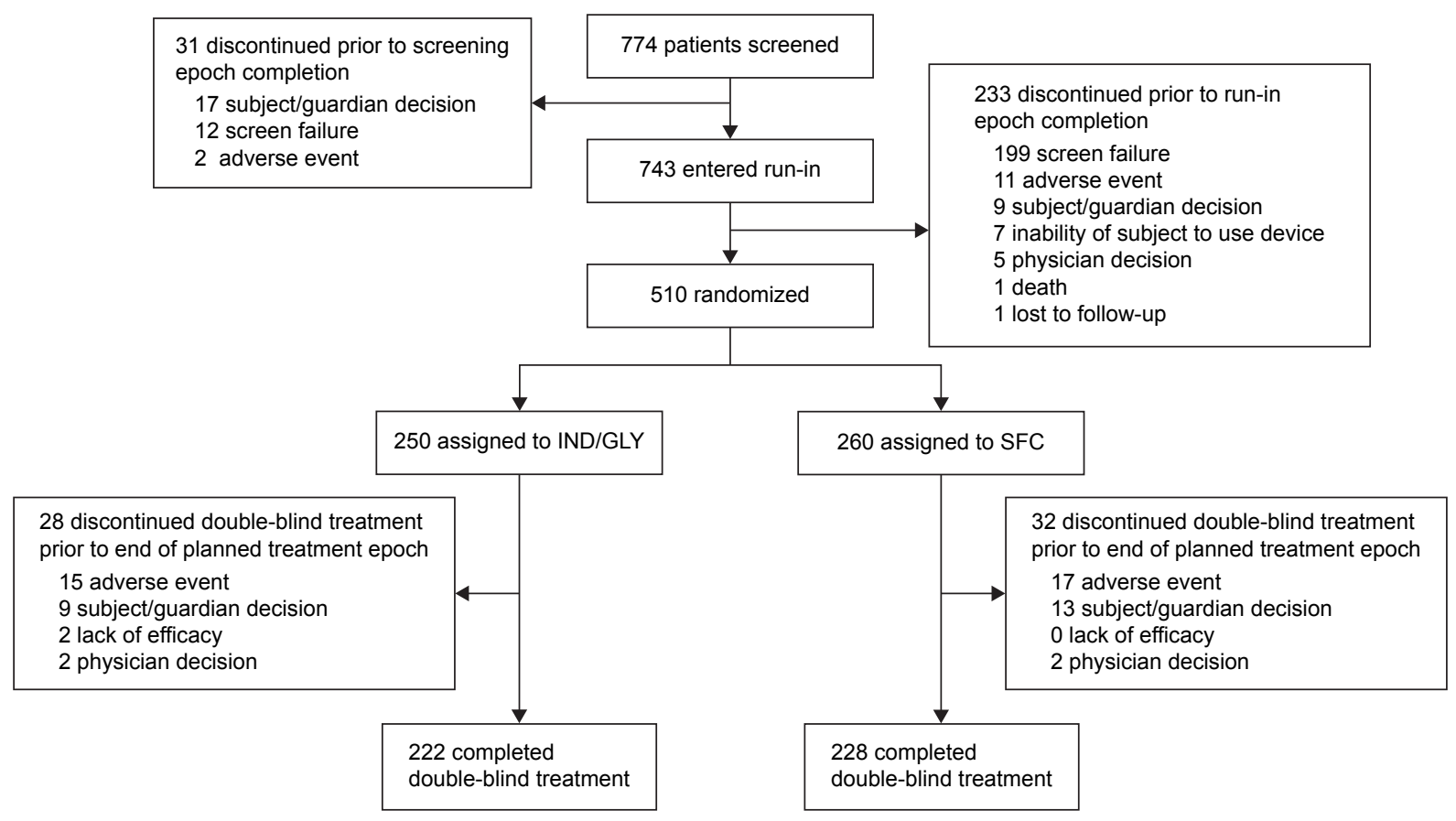

Figure I Patient disposition of Asian cohort from the FLAME study.

Note: Reasons are ordered by descending frequency in the IND/GLY group.

Abbreviations: GLY, glycopyrronium; IND, indacaterol; SFC, salmeterol/fluticasone propionate combination. 
Table I Baseline patient demographics and clinical characteristics of the FLAME overall population and Asian cohort

\begin{tabular}{|c|c|c|c|c|c|c|}
\hline \multirow[t]{2}{*}{ Characteristics } & \multicolumn{3}{|c|}{ Overall population } & \multicolumn{3}{|l|}{ Asian cohort } \\
\hline & $\begin{array}{l}\text { IND/GLY, } \\
\text { I I } 0 / 50 \mu \mathrm{g} \\
\text { q.d. }(\mathrm{n}=\mathrm{I}, 680)\end{array}$ & $\begin{array}{l}\text { SFC, } \\
50 / 500 \mu g \\
\text { b.i.d. }(n=I, 682)\end{array}$ & Total & $\begin{array}{l}\text { IND/GLY, } \\
\text { I I0/50 } \mu \mathrm{g} \\
\text { q.d. }(\mathrm{n}=\mathbf{2 5 0})\end{array}$ & $\begin{array}{l}\text { SFC, } \\
50 / 500 \mu g \\
\text { b.i.d. }(n=260)\end{array}$ & Total \\
\hline Age, years & $64.6(7.9)$ & $64.5(7.7)$ & $64.6(7.8)$ & $67.3(7.4)$ & $66.3(7.3)$ & $66.8(7.4)$ \\
\hline Male, n (\%) & $1,299(77.3)$ & $1,258(74.8)$ & $2,557(76.1)$ & $24 I(96.4)$ & $243(93.5)$ & $484(94.9)$ \\
\hline BMI $\left(\mathrm{kg} / \mathrm{m}^{2}\right)$ & $25.8(5.2)$ & $25.9(5.2)$ & $25.9(5.2)$ & $22.1(3.3)$ & $22.6(3.6)$ & $22.4(3.5)$ \\
\hline Duration of COPD, years & $7.2(5.3)$ & $7.3(5.5)$ & $7.3(5.4)$ & $5.6(4.6)$ & $5.9(4.7)$ & $5.8(4.6)$ \\
\hline ICS use at screening, $\mathrm{n}(\%)$ & $954(56.8)$ & $939(55.8)$ & $\mathrm{I}, 893(56.3)$ & $103(4 \mid .2)$ & $91(35.0)$ & $194(38.0)$ \\
\hline Current smoker, n (\%) & $664(39.5)$ & $669(39.8)$ & I,333 (39.6) & $66(26.4)$ & $70(26.9)$ & $136(26.7)$ \\
\hline \multicolumn{7}{|l|}{ Severity of COPD (GOLD 20I5), n (\%) } \\
\hline $\begin{array}{l}\text { Low risk and more symptoms } \\
\text { (Group B) }\end{array}$ & $400(23.8)$ & $422(25.1)$ & $822(24.4)$ & $42(16.8)$ & $67(25.8)$ & $109(21.4)$ \\
\hline $\begin{array}{l}\text { High risk and more symptoms } \\
\text { (Group D) }\end{array}$ & $1,265(75.3)$ & $1,249(74.3)$ & $2,5 \mid 4(74.8)$ & $206(82.4)$ & $191(73.5)$ & $397(77.8)$ \\
\hline \multicolumn{7}{|c|}{ Severity of airflow limitation (GOLD 20I I-20I4), n (\%) } \\
\hline Moderate (GOLD 2) & $560(33.3)$ & $563(33.5)$ & $\mathrm{I}, \mathrm{I} 23(33.4)$ & $67(26.8)$ & $85(32.7)$ & $152(29.8)$ \\
\hline Severe (GOLD 3) & $973(57.9)$ & $981(58.3)$ & I,954 (58.1) & $158(63.2)$ & $142(54.6)$ & $300(58.8)$ \\
\hline Very severe (GOLD 4) & $133(7.9)$ & $124(7.4)$ & $257(7.6)$ & $23(9.2)$ & $31(11.9)$ & $54(10.6)$ \\
\hline Prebronchodilator $\mathrm{FEV}_{1}, \mathrm{~L}$ & $1.0(0.3)$ & $1.0(0.3)$ & $\mathrm{I} .0(0.3)$ & $0.9(0.3)$ & $0.9(0.3)$ & $0.9(0.3)$ \\
\hline Postbronchodilator $\mathrm{FEV}_{\mathrm{l}}, \mathrm{L}$ & $1.2(0.3)$ & $1.2(0.4)$ & $1.2(0.4)$ & I.I $(0.3)$ & I.I (0.3) & I.I $(0.3)$ \\
\hline Postbronchodilator $\mathrm{FEV}_{1}, \%$ predicted & $44.0(9.5)$ & $44.1(9.4)$ & $44.1(9.5)$ & $43.1(9.6)$ & $42.4(10.1)$ & $42.7(9.8)$ \\
\hline $\begin{array}{l}\text { Postbronchodilator FEV, reversibility, } \\
\% \text { of baseline value }\end{array}$ & $22.2(16.0)$ & $22.5(16.0)$ & $22.4(16.0)$ & $23.1(14.6)$ & $24.3(16.8)$ & $23.7(15.7)$ \\
\hline Postbronchodilator $\mathrm{FEV}_{\mathrm{I}} / \mathrm{FVC}$, \% & $4 \mathrm{I} .7(9.8)$ & $4 I .5(9.9)$ & $41.6(9.9)$ & $37.5(8.3)$ & $38.2(9.4)$ & $37.9(8.9)$ \\
\hline \multicolumn{7}{|c|}{ Number of COPD exacerbations in the previous year, $n(\%)$} \\
\hline I & $1,355(80.7)$ & $1,355(80.6)$ & $2,710(80.6)$ & $202(80.8)$ & $213(81.9)$ & $415(81.4)$ \\
\hline$\geq 2$ & $324(19.3)$ & $325(19.3)$ & $649(19.3)$ & $48(19.2)$ & $47(18.1)$ & $95(18.6)$ \\
\hline CAT score & $16.9(7.1)$ & $16.6(7.0)$ & $16.7(7.1)$ & $14.2(6.7)$ & $14.2(6.8)$ & I $4.2(6.8)$ \\
\hline \multicolumn{7}{|l|}{ mMRC dyspnea scale, n (\%) } \\
\hline Grade 2 & $\mathrm{I}, 202(71.5)$ & $1,210(71.9)$ & $2,4 \mid 2(7 \mid .7)$ & 197 (78.8) & $198(76.2)$ & $395(77.5)$ \\
\hline Grade 3 & $439(26.1)$ & $432(25.7)$ & $871(25.9)$ & $5 I(20.4)$ & $59(22.7)$ & $110(21.6)$ \\
\hline Grade 4 & $36(2.1)$ & $38(2.3)$ & $74(2.2)$ & $2(0.8)$ & $3(1.2)$ & $5(1.0)$ \\
\hline
\end{tabular}

Note: Data are mean (SD) unless otherwise stated.

Abbreviations: b.i.d., twice daily; BMI, body mass index; CAT, COPD Assessment Test; FEV , forced expiratory volume in I second; FVC, forced vital capacity; GLY, glycopyrronium; GOLD, Global initiative for chronic Obstructive Lung Disease; ICS, inhaled corticosteroid; IND, indacaterol; mMRC, modified Medical Research Council; q.d., once daily; SD, standard deviation; SFC, salmeterol/fluticasone propionate combination.

in GOLD group D (77.8\%), with moderate-to-very severe airflow limitation and a mean postbronchodilator $\mathrm{FEV}_{1}$ of $42.7 \%$ of the predicted normal value. A total of $18.6 \%$ of patients had a history of $\geq 2$ moderate or severe exacerbations in the past year. Within the Asian cohort, there were no baseline imbalances in the proportion of patients who had a history of either 1 or 2 or more exacerbations in the previous year.

\section{Efficacy - COPD exacerbations}

IND/GLY significantly reduced the rate of moderate or severe exacerbations (health care utilization) by $25 \%$ (RR, 0.75; 95\% CI: 0.58-0.97; $P=0.027$; Figure 2) compared with SFC. The rate reduction with IND/GLY in the Asian cohort was comparable with that observed in the overall population (17\% reduction; Figure 2). Furthermore, the annualized rate of moderate or severe exacerbations was lower in the Asian cohort than in the overall population (Table S2). IND/GLY prolonged the time to first moderate or severe exacerbation with a $23 \%$ reduction in risk (180 days [95\% CI, 135-223] versus 148 days [95\% CI, 98-184]; HR, 0.77; 95\% CI, 0.59-1.01; $P=0.055$; Figure 3) versus $\mathrm{SFC}$, in line with the observations from the overall population (HR, 0.78; 95\% CI, 0.70-0.86; $P<0.001$ ). Less than $50 \%$ of patients in both treatment groups had an exacerbation; therefore, time to first moderate or severe exacerbation in the first quartile of patients was calculated instead of the median time. IND/GLY reduced the annualized rate of all (mild, moderate, or severe) COPD exacerbations versus SFC (RR, 0.94; 95\% CI: $0.76-1.16 ; P=0.567$ ) in the full analysis set of the Asian population. The rate of all (mild, moderate, or severe) COPD exacerbations was lower with both 

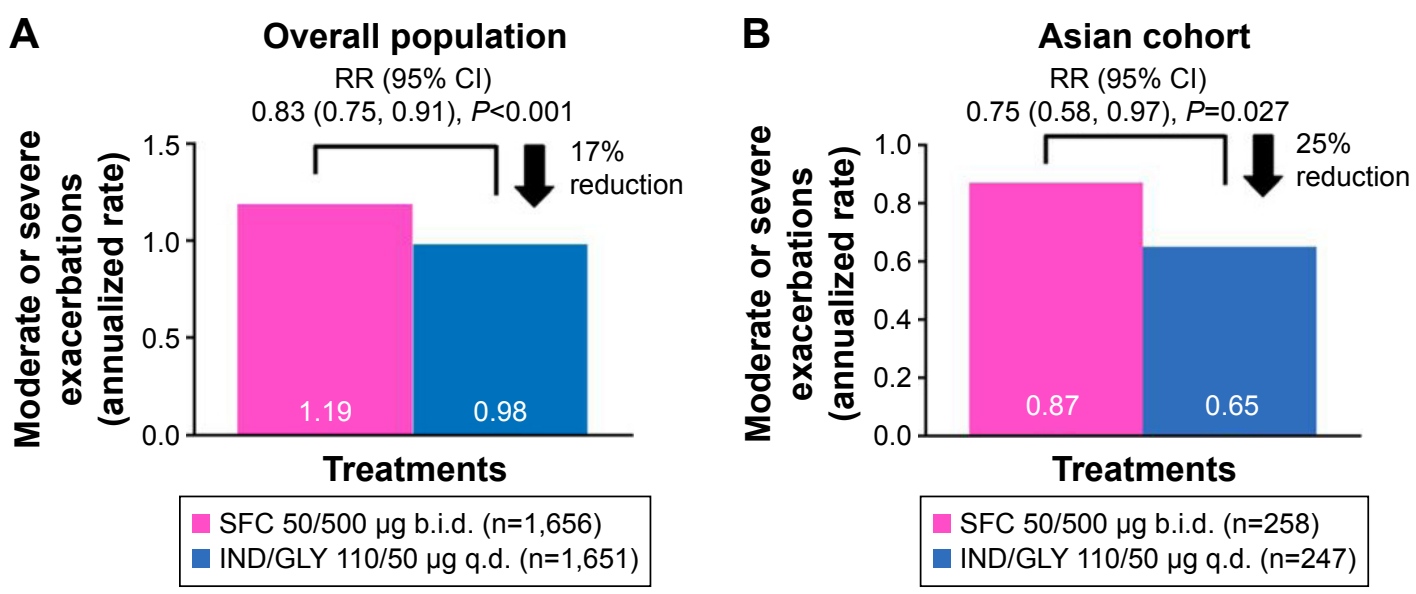

Figure 2 Rate of moderate or severe COPD exacerbations during 52 weeks of treatment (full analysis set).

Abbreviations: b.i.d., twice daily; $\mathrm{Cl}$, confidence interval; GLY, glycopyrronium; IND, indacaterol; q.d., once daily; RR, rate ratio; SFC, salmeterol/fluticasone propionate combination.

treatments in the Asian cohort compared with the overall population (Table S3).

\section{Efficacy - lung function}

Improvement in predose trough $\mathrm{FEV}_{1}$ was significantly greater with IND/GLY versus SFC, with a treatment difference of $53 \mathrm{~mL}$ at week $52(P<0.001)$. Treatment differences at all other time points were significant $(P<0.001)$, and a clear separation was seen between the 2 treatments from day 29, which was sustained until day 365 (Figure 4). Improvement in trough $\mathrm{FVC}$ at week 52 was also significantly greater with IND/GLY compared with SFC, with a treatment difference of $213 \mathrm{~mL}(P<0.001)$. Treatment differences

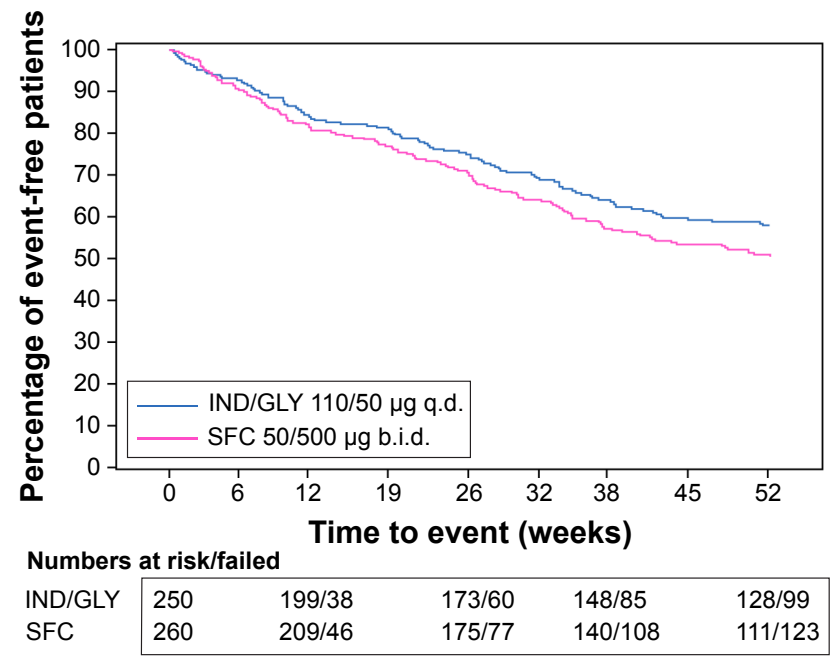

Figure 3 Kaplan-Meier plot of time to first moderate or severe COPD exacerbation during 52 weeks of treatment.

Abbreviations: GLY, glycopyrronium; IND, indacaterol; SFC, salmeterol/fluticasone propionate combination. at all other time points (weeks $4,12,26$, and 38) were also significant $(P<0.001)$.

\section{Efficacy - health status}

Improvement in SGRQ-C total score over the 52-week treatment period was greater with IND/GLY compared with SFC, with a treatment difference of -3.1 units at week 52 ( $P=0.006$; Figure $\mathrm{S} 1$ ). IND/GLY showed a greater improvement in SGRQ-C score versus SFC at week 52 in the Asian cohort compared with that observed in the overall population (-1.3 units).

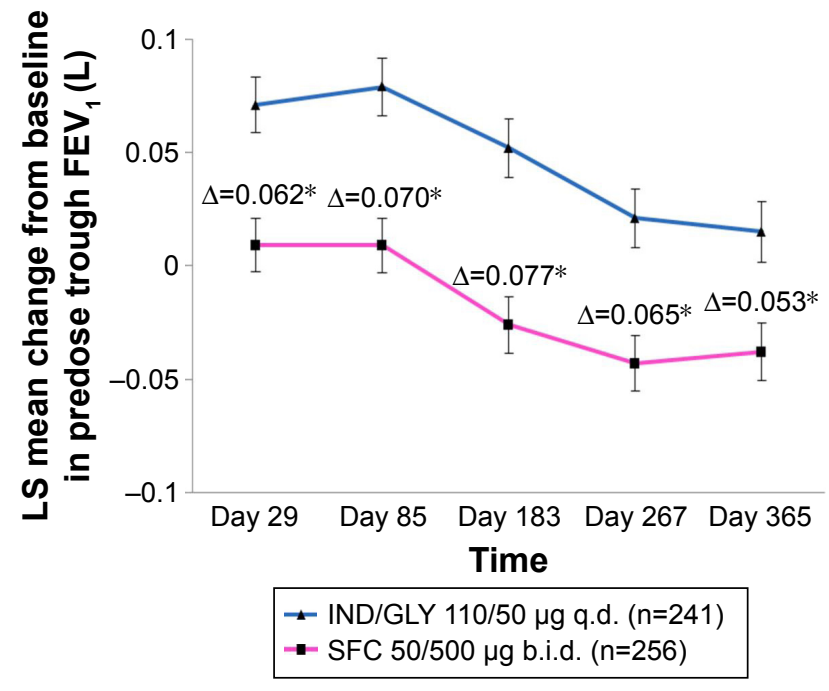

Figure 4 Change from baseline in predose trough FEV $(\mathrm{L})$ over treatment duration (full analysis set).

Notes: ${ }^{*} P<0.001 ; \Delta$, treatment difference.

Abbreviations: b.i.d., twice daily; $\mathrm{FEV}_{\mathrm{l}}$, forced expiratory volume in I second; GLY, glycopyrronium; IND, indacaterol; LS, least squares; q.d., once daily; SFC, salmeterol/fluticasone propionate combination. 


\section{Efficacy - rescue medication use}

Rescue medication use (puffs/day) was numerically reduced with IND/GLY versus SFC (treatment difference, $-0.25 ; 95 \%$ CI: -0.50 to $0.01 ; P=0.058$ ), and the change from baseline in percentage of rescue medication-free days was also numerically greater with IND/GLY compared with SFC (treatment difference, $2.7 ; 95 \% \mathrm{CI}:-2.2$ to $7.7 ; P=0.277$ ).

\section{Safety}

The incidence of AEs was similar between the IND/GLY and SFC groups. COPD was the most frequently reported $\mathrm{AE}$, and the incidence was similar between the 2 treatment groups (Table 2). The incidence of SAEs was numerically higher in the SFC group compared with the IND/GLY group. The number of patient deaths was comparable between the $\operatorname{IND} / \mathrm{GLY}(\mathrm{n}=4)$ and SFC $(\mathrm{n}=5)$ groups. The primary causes of deaths were cardiovascular and respiratory disorders. The incidence of pneumonia was numerically lower in the IND/GLY group compared with the SFC-treated patients (3.6 versus $7.7 \% ; P=0.046$ ), and this incidence was higher in the Asian cohort than in the overall study population (IND/ GLY, 3.2\%; SFC, 4.8\%). Additionally, IND/GLY delayed the time to first pneumonia (using the consolidated term of pneumonia [preferred terms of pneumonia, lung infection and pneumonia bacterial]) compared with SFC $(P=0.054)$. The incidence of other respiratory tract infections (including influenza) was numerically higher with SFC, as was the

Table 2 AEs by preferred term ( $\geq 3 \%$ in any treatment group) and SAEs (safety set)

\begin{tabular}{|c|c|c|}
\hline Parameter & $\begin{array}{l}\text { IND/GLY, } \\
\text { I I 0/50 } \mu \mathrm{g} \\
\text { q.d. }(\mathrm{n}=\mathbf{2 5 0})\end{array}$ & $\begin{array}{l}\text { SFC, } \\
50 / 500 \mu g \\
\text { b.i.d. }(n=260)\end{array}$ \\
\hline Patients with at least I AE & $206(82.4)$ & $222(85.4)$ \\
\hline COPD & $170(68.0)$ & $194(74.6)$ \\
\hline Nasopharyngitis & $40(16.0)$ & $42(16.2)$ \\
\hline Upper respiratory tract infection & $34(13.6)$ & $42(16.2)$ \\
\hline Pneumonia & $9(3.6)$ & $20(7.7)$ \\
\hline Oral candidiasis & $3(1.2)$ & $20(7.7)$ \\
\hline Viral upper respiratory tract infection & $12(4.8)$ & $14(5.4)$ \\
\hline $\begin{array}{l}\text { Upper respiratory tract infection } \\
\text { bacterial }\end{array}$ & $9(3.6)$ & $13(5.0)$ \\
\hline Bronchitis & $4(1.6)$ & $10(3.8)$ \\
\hline Cough & $8(3.2)$ & $10(3.8)$ \\
\hline Influenza & $3(1.2)$ & $8(3.1)$ \\
\hline $\begin{array}{l}\text { Patients with at least I AE suspected } \\
\text { to be treatment related }\end{array}$ & $21(8.4)$ & $35(13.5)$ \\
\hline Patients with at least I SAE & $43(17.2)$ & $70(26.9)$ \\
\hline Death & $4(1.6)$ & $5(1.9)$ \\
\hline
\end{tabular}

Notes: Data are $n(\%) ; n$, number of patients. All deaths were adjudicated. Abbreviations: AE, adverse event; b.i.d., twice daily; GLY, glycopyrronium; IND, indacaterol; q.d., once daily; SAE, serious adverse event; SFC, salmeterol/fluticasone propionate combination. incidence of oral candidiasis (IND/GLY, 1.2\%; SFC, 7.7\%). The incidence of MACEs was low and comparable between the treatment groups (IND/GLY, 1.2\%; SFC, 2.3\%); the incidence of cardiovascular deaths was the same in the 2 groups (IND/GLY, 0.4\%; SFC, 0.4\%).

\section{Discussion}

Acute COPD exacerbations cause considerable morbidity and mortality and incur significant health care utilization and associated costs. ${ }^{21,22}$ In this context, global treatment guidelines for COPD do not recommend region-specific treatment options; ${ }^{10}$ hence, regional guidelines draw heavily from the global guidelines for treatment recommendations. The great majority of data comparing therapeutic options has been generated in the Western population. Yet, Asian population differs from the Western population in disease reporting, socioeconomic factors as well as disease management practices; additionally, previous data suggest that disease manifestations may differ between these populations. ${ }^{23}$ Therefore, evaluation of efficacy and safety of therapeutic options in COPD patients from Asia are of considerable clinical importance to validate the treatment effects seen globally. ${ }^{24,25}$

FLAME was the first study which compared the effect of LABA/LAMA (IND/GLY 110/50 $\mu$ g q.d.) therapy versus LABA/ICS (SFC 50/500 $\mu$ g b.i.d.) evaluating exacerbations as the primary end point in COPD patients with moderate-tovery severe airflow limitation and with a high risk of future exacerbations. ${ }^{18}$ This analysis of FLAME study data provides an insight into treatment effects in Asian patients relative to those in other regions in terms of response to LABA/LAMA dual bronchodilator therapy versus LABA/ICS combination therapy. It is notable that the rate of exacerbations in both treatment groups was lower in the Asian cohort than in the overall population. Such lower frequency of exacerbations compared with the total population was also observed in similar cohort analyses of Japanese patients participating in the UPLIFT trial ${ }^{26}$ and in another Japanese cohort study. ${ }^{27}$

In the Asian cohort, IND/GLY was superior to SFC in providing statistically significant reduction in the rate of moderate or severe COPD exacerbations, which is important since reduced risk of these exacerbations is linked with decreased morbidity, mortality, and health care costs in COPD patients. ${ }^{28}$ This finding is consistent with the overall study findings and with those from a previous study in exacerbating patients in which IND/GLY significantly reduced the risk of moderate or severe exacerbation versus LABA/ICS in predominantly Chinese patients with 
moderate-to-severe COPD..$^{15}$ The results are also in line with previous reports where effect of IND/GLY on exacerbations was superior to LAMA monotherapy in patients with severeto-very severe COPD. ${ }^{29}$ Furthermore, IND/GLY prolonged the time to first moderate or severe COPD exacerbation versus SFC in Asian patients with an effect similar to that seen in the overall study population. The reduced time to exacerbation with IND/GLY in this cohort is notable because it is the first LABA/LAMA to demonstrate this, whereas another LABA/LAMA umeclidinium/vilanterol failed to prolong time to first exacerbation versus placebo at $62.5 / 25 \mu \mathrm{g}$ (its approved dose in Asia) in Asian patients. ${ }^{30} \mathrm{In}$ the Asian cohort, the effect of IND/GLY compared with SFC in reducing the rate of all (mild, moderate, or severe) COPD exacerbations was comparable to that seen in the overall FLAME study; however, statistical significance could not be reached in this cohort, which represented $<20 \%$ of the overall study population. This may also be due to the smaller effect observed with all exacerbations in the Asian cohort compared with the overall study population.

IND/GLY also provided consistently superior improvement in lung function over the study duration. Furthermore, exacerbations and health status are closely related, ${ }^{19}$ and reducing exacerbations improves health status. IND/GLY improved the health status of patients, as evident in the improvements in SGRQ-C total scores throughout the treatment duration. Symptomatic benefits with IND/GLY were seen in terms of reduced rescue medication use compared with SFC. These findings are also consistent with the results of previous studies conducted in predominantly Caucasian patients with COPD, which also indicated improvements in lung function, symptoms, and health status with once-daily IND/GLY compared with SFC in patients with or without a history of COPD exacerbations. ${ }^{14,31}$ Overall, the pattern of response to IND/GLY treatment in Asian patients for efficacy parameters was generally comparable with that observed in the overall population. Furthermore, it has been previously shown that in patients with severe COPD receiving LABA/ LAMA therapy along with ICS, the risk of moderate or severe exacerbations was similar among those who discontinued ICS and those who continued ICS; therefore, ICS therapy may not be essential in these patients. ${ }^{32}$

Once-daily IND/GLY was well tolerated with a good safety profile in terms of incidence of AEs, SAEs, deaths, and MACEs, similar to that reported previously. ${ }^{33,34}$ The incidence of AEs with IND/GLY and SFC was comparable; no new safety concerns were identified. Importantly, the risk of pneumonia was less with IND/GLY compared with SFC. ICS therapy has been shown to be associated with an increased risk of pneumonia in patients with COPD, ${ }^{35,36}$ which was reflected in this study where a 2-fold higher incidence of pneumonia was reported with SFC compared with IND/GLY. Again, it is notable that pneumonia was reported more commonly in the Asian cohort than in the overall study population.

Our findings indicate that together with the exacerbation outcomes and lowered risk of pneumonia, LABA/ LAMA therapy could be positioned as potential first-line maintenance treatment option in COPD treatment guidelines, especially in the context of the Asian population. ${ }^{37-39}$

\section{Conclusion}

Despite minor differences in baseline characteristics and perceived influence of interethnic differences between the Asian and overall populations of the FLAME study, IND/ GLY 110/50 $\mu$ g q.d. showed generally similar reductions in moderate or severe COPD exacerbations, improved lung function, and improved health status versus SFC in the Asian cohort when compared with the total FLAME population. An overall benefit was observed with a reduced risk of pneumonia and with no other discernible safety concern for IND/ GLY. These findings represent important new evidence in the pharmacological management of COPD. Results of this Asian cohort analysis combined with the overall FLAME results and previous findings from LANTERN shed new light and expand the evidence for dual bronchodilator therapy to be the first-line treatment option in symptomatic COPD patients at risk for future exacerbations in different regions, especially in Asia.

\section{Abbreviations}

AE, adverse event; b.i.d., twice daily; BMI, body mass index; CXR, chest X-ray; $\mathrm{FEV}_{1}$, forced expiratory volume in 1 second; FVC, forced vital capacity; GOLD, Global initiative for chronic Obstructive Lung Disease; GLY, glycopyrronium; $\mathrm{HR}$, hazard ratio; ICS, inhaled corticosteroid; IEC, Independent Ethics Committee; IND, indacaterol; IRB, Institutional Review Board; LABA, long-acting $\beta_{2}$-agonist; LAMA, long-acting muscarinic antagonist; MACE, major adverse cardiovascular event; mMRC, modified Medical Research Council; q.d., once daily; RR, rate ratio; SAE, serious adverse event; SFC, salmeterol/fluticasone propionate combination; SGRQ-C, St George's Respiratory Questionnaire for COPD.

\section{Acknowledgments}

The authors would like to thank the patients and staff at participating centers in this study. The authors were assisted in 
the preparation of this manuscript by Rahul Lad, Professional Medical Writer (Novartis). The study was funded by Novartis Pharma AG, Basel, Switzerland.

\section{Author contributions}

JAW, NZ, MI, MH, RF, CT, FP, and DB all made substantial contributions to the conception and design of the study, the acquisition, analysis, and interpretation of data. All authors contributed toward the drafting of the article and revising it critically for important intellectual content. All authors provided their final approval of the version to be published. The authors are accountable for the accuracy and integrity of this work.

\section{Disclosure}

JAW has received no honoraria from industry for lectures and/or advisory boards from January 2015. Prior to January 2015 she received honoraria for lectures and/or advisory boards from Novartis, GSK, Astra Zeneca, Boehringer Ingelheim, Takeda, and Johnson and Johnson. JAW has received research grant funding in the last 3 years from Johnson and Johnson, Takeda, GSK, and Vifor Pharma. MI has served on Scientific Advisory Boards for AstraZeneca, Nippon Boehringer Ingelheim, and Novartis Pharma KK from January 2015. MI has received honoraria for speaking from AstraZeneca, GSK, Nippon Boehringer Ingelheim, Kyorin, and Novartis Pharma in 2015. NZ does not have any competing interests to declare. $\mathrm{MH}, \mathrm{RF}, \mathrm{CT}, \mathrm{FP}$, and DB are Novartis employees. The authors report no other conflicts of interest in this work.

\section{References}

1. Lopez-Campos JL, Tan W, Soriano JB. Global burden of COPD. Respirology. 2016;21(1):14-23.

2. World Health Organization [webpage on the Internet]. Global Burden of Chronic Respiratory Disease. 2016. Available from: http://www.who. int/respiratory/copd/burden/en/. Accessed May 3, 2016.

3. Oh YM, Bhome AB, Boonsawat W, et al. Characteristics of stable chronic obstructive pulmonary disease patients in the pulmonology clinics of seven Asian cities. Int J Chron Obstruct Pulmon Dis. 2013;8: 31-39.

4. Lim S, Lam DC, Muttalif AR, et al. Impact of chronic obstructive pulmonary disease (COPD) in the Asia-Pacific region: the EPIC Asia population-based survey. Asia Pac Fam Med. 2015;14(1):4.

5. Tan WC, Seale P, Ip M, et al. Trends in COPD mortality and hospitalizations in countries and regions of Asia-Pacific. Respirology. 2009; 14(1):90-97.

6. Zhong N, Wang C, Yao W, et al. Prevalence of chronic obstructive pulmonary disease in China: a large, population-based survey. Am J Respir Crit Care Med. 2007;176(8):753-760.

7. Caramori G, Adcock IM, Papi A. Clinical definition of COPD exacerbations and classification of their severity. South Med J. 2009;102(3): 277-282.

8. Anzueto A. Impact of exacerbations on COPD. Eur Respir Rev. 2010; 19(116):113-118.
9. Wedzicha JA, Seemungal TA. COPD exacerbations: defining their cause and prevention. Lancet. 2007;370(9589):786-796.

10. Global Initiative for Chronic Obstructive Lung Disease (GOLD) [homepage on the Internet]. The Global Strategy for the Diagnosis, Management and Prevention of COPD. 2016. Available from: http:// www.goldcopd.org. Accessed 3 May 2016.

11. National Institute for Health and Care Excellence (NICE). Chronic Obstructive Pulmonary Disease. Management of Chronic Obstructive Pulmonary Disease in Adults in Primary and Secondary Care. NICE Clinical Guideline 101 (Partial Update). London: National Institute for Health and Care Excellence (NICE); 2010.

12. Crim C, Calverley PM, Anderson JA, et al. Pneumonia risk in COPD patients receiving inhaled corticosteroids alone or in combination: TORCH study results. Eur Respir J. 2009;34(3):641-647.

13. Suissa S, Patenaude V, Lapi F, Ernst P. Inhaled corticosteroids in COPD and the risk of serious pneumonia. Thorax. 2013;68(11):1029-1036.

14. Matera MG, Rogliani P, Cazzola M. QVA149 (indacaterol/ glycopyrronium) for the treatment of chronic obstructive pulmonary disease. Expert Opin Pharmacother. 2015;16(7):1079-1090.

15. Zhong N, Wang C, Zhou X, et al. LANTERN: a randomized study of QVA149 versus salmeterol/fluticasone combination in patients with COPD. Int J Chron Obstruct Pulmon Dis. 2015;10:1015-1026.

16. Asai K, Minakata Y, Hirata K, et al. QVA149 once-daily is safe and well tolerated and improves lung function and health status in Japanese patients with COPD: the ARISE study. Eur Repir J. 2013;42:3392.

17. Hashimoto S, Ikeuchi H, Murata S, Kitawaki T, Ikeda K, Banerji D. Efficacy and safety of indacaterol/glycopyrronium in Japanese patients with COPD: a subgroup analysis from the SHINE study. Int J Chron Obstruct Pulmon Dis. 2016;11:2543-2551.

18. Wedzicha JA, Banerji D, Chapman KR, et al. Indacaterolglycopyrronium versus salmeterol-fluticasone for COPD. N Engl J Med. 2016;374(23):2222-2234.

19. Seemungal TA, Donaldson GC, Paul EA, Bestall JC, Jeffries DJ, Wedzicha JA. Effect of exacerbation on quality of life in patients with chronic obstructive pulmonary disease. Am J Respir Crit Care Med. 1998; 157:1418-1422.

20. Anthonisen NR, Manfreda J, Warren CP, Hershfield ES, Harding GK, Nelson NA. Antibiotic therapy in exacerbations of chronic obstructive pulmonary disease. Ann Intern Med. 1987;106:196-204.

21. Hurst JR, Vestbo J, Anzueto A, et al. Susceptibility to exacerbation in chronic obstructive pulmonary disease. $N$ Engl J Med. 2010;363(12): $1128-1138$.

22. Blasi F, Cesana G, Conti S, et al. The clinical and economic impact of exacerbations of chronic obstructive pulmonary disease: a cohort of hospitalized patients. PLoS One. 2014;9(6):e101228.

23. Tan WC, Ng TP. Where east meets west. Chest. 2008;133:517-527.

24. Yasuda SU, Zhang L, Huang SM. The role of ethnicity in variability in response to drugs: focus on clinical pharmacology studies. Clin Pharmacol Ther. 2008;84(3):417-423.

25. Martin A, Badrick E, Mathur R, Hull S. Effect of ethnicity on the prevalence, severity, and management of COPD in general practice. Br J Gen Pract. 2012;62(595):e76-e81.

26. Fukuchi Y, Fernandez L, Kuo HP, et al. Efficacy of tiotropium in COPD patients from Asia: a subgroup analysis from the UPLIFT trial. Respirology. 2011;16(5):825-835.

27. Suzuki M, Makita H, Ito YM, et al; Hokkaido COPD Cohort Study Investigators. Clinical features and determinants of COPD exacerbation in the Hokkaido COPD cohort study. Eur Respir J. 2014;43(5):1289-1297.

28. Seemungal TA, Hurst JR, Wedzicha JA. Exacerbation rate, health status and mortality in COPD - a review of potential interventions. Int J Chron Obstruct Pulmon Dis. 2009;4:203-223.

29. Wedzicha JA, Decramer M, Ficker JH, et al. Analysis of chronic obstructive pulmonary disease exacerbations with the dual bronchodilator QVA149 compared with glycopyrronium and tiotropium (SPARK): a randomised, double-blind, parallel-group study. Lancet Respir Med. 2013;1(3):199-209. 
30. Zheng J, Zhong N, Newlands A, Church A, Goh AH. Efficacy and safety of once-daily inhaled umeclidinium/vilanterol in Asian patients with COPD: results from a randomized, placebo-controlled study. Int J Chron Obstruct Pulmon Dis. 2015;10:1753-1767.

31. Vogelmeier CF, Bateman ED, Pallante J, et al. Efficacy and safety of once-daily QVA149 compared with twice-daily salmeterol-fluticasone in patients with chronic obstructive pulmonary disease (ILLUMINATE): a randomised, double-blind, parallel group study. Lancet Respir Med. 2013;1(1):51-60.

32. Magnussen H, Disse B, Rodriguez-Roisin R, et al. Withdrawal of inhaled glucocorticoids and exacerbations of COPD. $N$ Engl J Med. 2014;371(14):1285-1294.

33. Wedzicha JA, Dahl R, Buhl R, et al. Pooled safety analysis of the fixeddose combination of indacaterol and glycopyrronium (QVA149), its monocomponents, and tiotropium versus placebo in COPD patients. Respir Med. 2014;108(10):1498-1507.

34. Dahl R, Chapman KR, Rudolf M, et al. Safety and efficacy of dual bronchodilation with QVA149 in COPD patients: the ENLIGHTEN study. Respir Med. 2013;107(10):1558-1567.
35. DiSantostefano RL, Sampson T, Le HV, Hinds D, Davis KJ Bakerly ND. Risk of pneumonia with inhaled corticosteroid versus long-acting bronchodilator regimens in chronic obstructive pulmonary disease: a new-user cohort study. PLoS One. 2014;9(5):e97149.

36. Ernst P, Saad N, Suissa S. Inhaled corticosteroids in COPD: the clinical evidence. Eur Respir J. 2015;45(2):525-537.

37. Hizawa N. LAMA/LABA vs ICS/LABA in the treatment of COPD in Japan based on the disease phenotypes. Int J Chron Obstruct Pulmon Dis. 2015;10:1093-1102.

38. Horita N, Kaneko T. Role of combined indacaterol and glycopyrronium bromide (QVA149) for the treatment of COPD in Japan. Int J Chron Obstruct Pulmon Dis. 2015;10:813-822.

39. Singh D. New combination bronchodilators for chronic obstructive pulmonary disease: current evidence and future perspectives. Br J Clin Pharmacol. 2015;79(5):695-708. 


\section{Supplementary materials}

Table SI Number of patients from each Asian country by treatment

\begin{tabular}{|c|c|c|c|}
\hline Country & IND/GLY, I I 0/50 $\mu$ g q.d. (n=250), n (\%) & SFC, $50 / 500 \mu$ g b.i.d. $(n=260), n$ (\%) & Total $(\mathrm{N}=5 \mid 0), \mathrm{n}(\%)$ \\
\hline China & $148(59.2)$ & $147(56.5)$ & $295(57.8)$ \\
\hline Hong Kong & $2(0.8)$ & $3(1.2)$ & $5(1.0)$ \\
\hline Japan & $40(16.0)$ & $40(15.4)$ & $80(15.7)$ \\
\hline Korea & $32(12.8)$ & $39(15.0)$ & $71(13.9)$ \\
\hline Philippines & $13(5.2)$ & $22(8.5)$ & $35(6.9)$ \\
\hline Thailand & $4(1.6)$ & $4(1.5)$ & $8(1.6)$ \\
\hline Taiwan & II (4.4) & $5(1.9)$ & $16(3.1)$ \\
\hline
\end{tabular}

Abbreviations: GLY, glycopyrronium; IND, indacaterol; SFC, salmeterol/fluticasone propionate combination.

Table S2 Moderate or severe COPD exacerbations during double-blind treatment (full analysis set)

\begin{tabular}{|c|c|c|c|c|c|}
\hline Treatment & $\begin{array}{l}\text { Patients with } \\
\text { exacerbation, } \mathbf{n}(\%)\end{array}$ & $\begin{array}{l}\text { Total number of COPD } \\
\text { exacerbation episodes }\end{array}$ & $\begin{array}{l}\text { Occurrence rate in } \\
100 \text { patient years }\end{array}$ & $\begin{array}{l}\text { Annualized } \\
\text { rate; } 95 \% \mathrm{Cl}\end{array}$ & $\begin{array}{l}\text { Rate ratio (IND/GLY versus } \\
\text { SFC); } 95 \% \mathrm{CI} \text {; } P \text {-value }\end{array}$ \\
\hline \multicolumn{6}{|c|}{ Overall population } \\
\hline IND/GLY & $737(44.0)$ & 1,265 & 84.10 & $0.98(0.88,1.10)$ & $0.83(0.75,0.91) ; P<0.001$ \\
\hline SFC & $844(50.3)$ & $\mathrm{I}, 452$ & 98.20 & $1.19(1.07,1.32)$ & \\
\hline \multicolumn{6}{|l|}{ Asian cohort } \\
\hline IND/GLY & 99 (39.6) & 166 & 72.20 & $0.65(0.5 \mathrm{I}, 0.83)$ & $0.75(0.58,0.97) ; P=0.027$ \\
\hline SFC & I $24(47.7)$ & 238 & 97.44 & $0.87(0.70,1.08)$ & \\
\hline
\end{tabular}

Note: IND/GLY I I0/50 $\mu$ g q.d.; SFC 50/500 $\mu$ g b.i.d.

Abbreviations: GLY, glycopyrronium; IND, indacaterol; SFC, salmeterol/fluticasone propionate combination.

Table S3 COPD exacerbations (mild, moderate, or severe) during double-blind treatment (full analysis set)

\begin{tabular}{|c|c|c|c|c|c|}
\hline Treatment & $\begin{array}{l}\text { Patients with } \\
\text { exacerbation, n (\%) }\end{array}$ & $\begin{array}{l}\text { Total number of COPD } \\
\text { exacerbation episodes }\end{array}$ & $\begin{array}{l}\text { Occurrence rate in } \\
100 \text { patient years }\end{array}$ & $\begin{array}{l}\text { Annualized } \\
\text { rate; } 95 \% \mathrm{Cl}\end{array}$ & $\begin{array}{l}\text { Rate ratio (IND/GLY versus } \\
\text { SFC); } 95 \% \mathrm{CI} \text {; } P \text {-value }\end{array}$ \\
\hline \multicolumn{6}{|c|}{ Overall population } \\
\hline IND/GLY & $\mathrm{I}, 295(77.3)$ & 4,943 & 328.62 & $3.59(3.29,3.92)$ & $0.88(0.82,0.94) ; P<0.001$ \\
\hline SFC & $\mathrm{I}, 368(81.5)$ & 5,438 & 367.76 & $4.09(3.75,4.46)$ & \\
\hline \multicolumn{6}{|c|}{ Asian population } \\
\hline IND/GLY & $169(67.6)$ & 513 & 223.12 & $2.4 I(2.00,2.92)$ & $0.94(0.76,1.16) ; P=0.567$ \\
\hline SFC & $192(73.8)$ & 594 & 243.19 & $2.57(2.15,3.06)$ & \\
\hline
\end{tabular}

Note: IND/GLY I I0/50 $\mu$ g q.d.; SFC 50/500 $\mu$ g b.i.d.

Abbreviations: GLY, glycopyrronium; IND, indacaterol; SFC, salmeterol/fluticasone propionate combination.

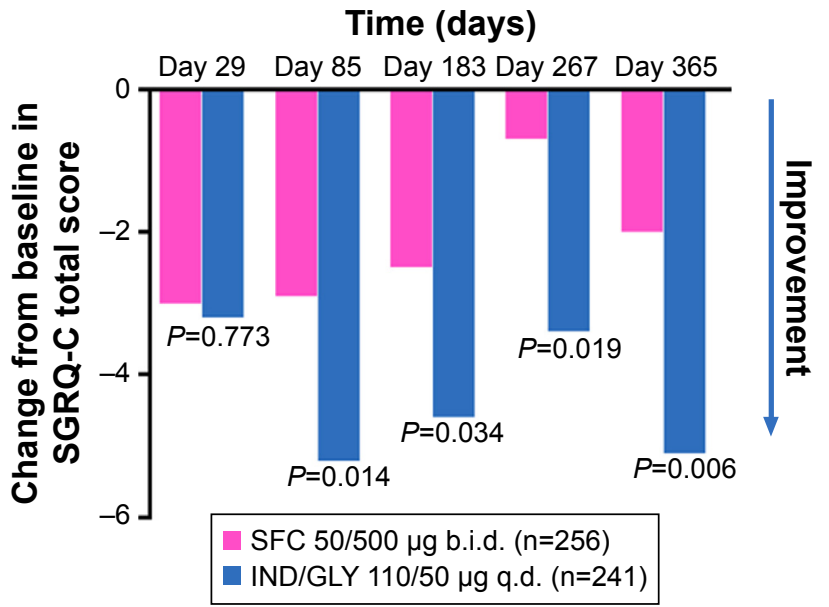

Figure SI Adjusted mean change from baseline in SGRQ-C total score over 52 weeks (full analysis set).

Abbreviations: b.i.d., twice daily; GLY, glycopyrronium; IND, indacaterol; q.d., once daily; SFC, salmeterol/fluticasone propionate combination; SGRQ-C, St George's Respiratory Questionnaire for COPD. 
International Journal of COPD

\section{Publish your work in this journal}

The International Journal of COPD is an international, peer-reviewed journal of therapeutics and pharmacology focusing on concise rapid reporting of clinical studies and reviews in COPD. Special focus is given to the pathophysiological processes underlying the disease, intervention programs, patient focused education, and self management protocols.

This journal is indexed on PubMed Central, MedLine and CAS. The manuscript management system is completely online and includes a very quick and fair peer-review system, which is all easy to use. Visit http://www.dovepress.com/testimonials.php to read real quotes from published authors 